\title{
Strongyloides stercoralis in an urban slum community in Bangladesh: factors independently associated with infection
}

Andrew Hall ${ }^{1}, 2$, David J. Conway ${ }^{2 *}$, Kazi Selim Anwar ${ }^{1}$ and Md Lutfar Rahman ${ }^{1}{ }^{1}$ International Centre for Diarthoeal Disease Research, Bangladesh (ICDDR,B), G.P.O. Box 128, Dhaka 1000, Bangladesh; ${ }^{2}$ Wellcome Research Centre for Parasitic Infections, Department of Biology, Imperial College, Prince Consort Road, Lóndon, $S W 72 B B, U K$

\section{Abstract}

Stool samples from 880 residents in an urban slum in Dhaka, Bangladesh, were collected on 3 occasions over one year, and examined for intestinal parasites. Information on many potential risk factors for infection was obtained by questionnaire from a respondent in each household studied. In a crude univariate analysis of the data, several of the factors were found to be significantly associated with Strongyloides stercoralis infection. Most of these factors were co-variate with one another, and with poverty generally. Using MantelHaenszel $\chi^{2}$ tests to control for confounding effects of each variable individually, the following 4 factors remained independently associated with $S$.stercoralis infection: respondent's use of a community latrine rather than a private latrine, living in a house with an earth floor rather than a cement floor, being of Bihari ethnicity, and being 7-10 years of age. Implications of these results for the epidemiology and control of strongyloidiasis are briefly discussed.

\section{Introduction}

The intestinal nematode Strongyloides stercoralis is endemic in many communities throughout tropical and temperate regions, and is responsible for a wide range of symptoms (GROVE, 1989a). The transmission of S. stercoralis involves contamination of the environment by firststage rhabditiform larvae from the faeces of infected people. Third-stage infective filariform larvae may mature within $24-48 \mathrm{~h}$ by direct development from rhabditiform larvae, or in 2-6 d by indirect development involving a single free-living generation. Infection occurs by skin penetration.

It is expected that risk factors for S. stercoralis infection may include poor personal hygiene and household sanitation, although the importance of specific factors has not been formally investigated. Some studies have suggested that earth floors offer a potentially suitable environment for transmission of infection within households (FAUST \& GIRALDO, 1960), and that infection may be aggregated in certain households (SOROCZAN, 1976; LINDO, 1992). The most compelling evidence for the importance of hygenic and sanitary factors is that high prevalences of infection (>20\%) are frequently recorded in institutions in which the personal hygiene of residents is severely im. paired (BANKI et al., 1963; Yoeli et al., 1963; Proxho. ROV et al., 1978; CoRNEJo et al., 1985).

As part of a study of reinfection with Ascaris lumbricoides among people living in an urban slum in Bangladesh (HALL et al., 1992), information was collected on other intestinal infections, and on factors which could influence individuals' exposure to these infections. The data were analysed to determine the distribution of S.stercoralis infection, and to examine potential risk factors for infection.

\section{Subjects and Methods}

Parasitological survey

The study was undertaken among residents of a slum community in Mirpur, a suburb of Dhaka, Bangladesh. The study was primarily designed to examine reinfection with $A$. lumbricoides, and had been approved by the Ethical Review Committee of the International Centre for Diarrhoeal Disease Research, Bangladesh (ICDDR,B). The majority of subjects were Bihari refugees who had sertled in camps after the war of independence from Pakistan in 1971 (WHITAKER et al., 1982).

Three faecal samples were collected over one year from each of 880 individuals living in 280 households, at intervals of 6 months. The samples were fixed in $10 \% \mathrm{v} / \mathrm{v}$ formalin in saline $(0.9 \% \mathrm{w} / \mathrm{v} \mathrm{NaCl})$, and processed by a

*Present address, for correspondence: Department of Clinical Sciences, London School of Hygiene and Tropical Medicine, Keppel Street, London, WC1E 7HT, UK. quantitative ether sedimentation technique (HALL, 1981) before being examined microscopically for the eggs of A.lumbricoides and other intestinal parasites. The presence of larvae of $S$. stercoralis was also recorded. Each subject was subsequently treated with a single dose of 1 I $\mathrm{mg} / \mathrm{kg}$ body weight of pyrantel pamoate (Combantrin ${ }^{\star}$; Pfizer, Bangladesh) in order to expel A.lumbricoides (see HaLL et al., 1992). Pyrantel is considered to be ineffective against $S$ stercoralis (see GROVE, 1989b). Specific treatment for Strongyloides was not given since the data were analysed retrospectively, after the Ascaris study had been completed.

Identification of factors associaked with S.stercoralis infection

A questionnaire administered to the wife of the principal male member of each household, termed the respondent, was used to collect the following information age, sex, and ethnic origin (Bangladeshi or Bihari) of all people living in the household; the number of years of residence in the area; the type of floor (earth or cement); the type of roof (bamboo, metal, or cement); the main source of water for drinking or washing (an owned or shared well, tube well or tap); the usual site of defaecation of the respondent and her children (indiscrimately, or in a community latrine, a latrine shared between neighbours, or a privately owned latrine); the respondent's reported ability to read (yes or no); and the estimated total monthly income of the household in Bangladesh taka (BDT). The proportion of subjects infected with $S$.stercoralis, defined as those in whose faeces larvae were seen at any of the 3 microscopical examinations, was tested for associations with each of these variables, and also with the A.lumbricoides worm burden, and the presense or absence of hookworm infection at the first examination, by calculating odds ratios with $95 \%$ confidence intervals, and by $\chi^{2}$ tests. Variables which were recorded as continuous values were converted to categorical formats for analysis. Each of the variables which was significantly associated with $S$.stercoralis infection in the crude analysis was then re-tested for association with infection, using Mantel-Haenszel $\chi^{2}$ tests to control for the effects of the other variables individually (KIRKW'OOD, 1988).

Results

Detection of S. stercoralis infection

One hundred and two of 880 subjects $(11.6 \%)$ had a detectable infection with $S$. stercoralis at at least one of the 3 six-monthly examinations; $34(3.9 \%)$ at the first examination, $43(4.9 \%)$ at the second, and $44(5.0 \%)$ at the third. The Figure shows the proportion of individuals in whose faeces S.stercoralis larvae were detected at each or any of the examinations, according to mean age at first 


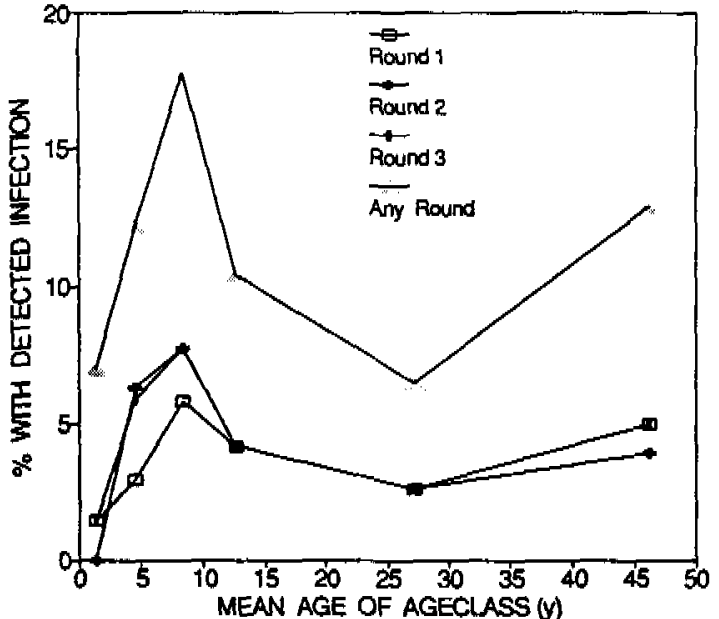

Figure. Percentage of individuals with detectable S. stercoralis infection (single stool examination after formalin-ether concentration) al each, or any, of the six-monthly examinations, according to age class (i.e., $<2,3$ $6,7-10,11-16,17-36$, or $>37$ years old).

examination. The peak proportion at any examination occurred in the 7-10 years age class, and was significantly greater than that in all combined younger and older age classes $(P<0-05$ for each comparison). The lowest proportions infected were in the $<2$ and $17-36$ years age classes, and they were significantly lower than in the 7,10 years age class $(P<0.005$ for each comparison).

Factors associated with S.stercoralis infection

Several factors were associated with a greater risk of being infected at any of the 3 examinations (Table). Those with the most highly significant associations $(P<0.005)$ were the use of a community latrine rather than a private latrine by respondents or children, and living in a house with an earth floor rather than a cement floor. Other factors associated with infection were Bihari ethricity $(P<0.01)$, a household size of 5 or more persons $(P<0.05)$, inability of the respondent to read $(P<0.05)$, living in a house with a metal roof rather than a cement roof $(P<0.05)$ defaecating indiscriminately rather than in a private latrine by children $(P<0.05)$, presence of hookworm infection $(P<0.05)$, having not more than the median household monthly incorne $(P<0.05)$ and, as mentioned above, being $7-10$ years of age $(P<0.05)$.

Many of these factors co-varied with one another, strongly suggesting that confounding was responsible for some of the observed associations. Therefore each of the variables associated with $S$.stercoralis infection in the crude analysis was further tested for association with infection after controlling for the effects of each of the other variables individually, using Mantel-Haenszel $\gamma^{2}$ tests. The variables which remained significantly associated with infection $(P<0.05)$ after controlling for each of the others individually were respondent's use of a community latrine rather than a private latrine, living in a house with an earth floor rather than a cement floor, being of Bihari ethnicity, and being 7-10 years of age.

\section{Discussion}

Infections with $S$.stercoralis were found to be associated with certain factors related to domestic hygiene. The 2 factors which were most significantly, and independently, associated with infection were the use of a community latrine, rather than a privately owned latrine, and having an earth floor rather than a cement floor in the house. The high risk of infection associated with use of a community latrine may be due to the likelihood that
Table. Proportion of individuals infected with $\boldsymbol{S}$. stercoralis (at any of three six-monthly examinations) according to potential risk factors

\begin{tabular}{|c|c|c|}
\hline & No. infected & Odds ratio \\
\hline $\begin{array}{l}\text { Age } \\
1-6 \text { years } \\
7-10 \text { years } \\
>10 \text { years }\end{array}$ & $\begin{array}{l}27 / 273(9 \cdot 9 \%) \\
37 / 208(17 \cdot 8 \%) \\
38 / 399(9 \cdot 5 \%)\end{array}$ & $\begin{array}{l}1.97(1 \cdot \overline{16-3.33} \\
0.96(0.54-1.70)\end{array}$ \\
\hline $\begin{array}{l}\text { Sex } \\
\text { Female } \\
\text { Male }\end{array}$ & $\begin{array}{l}53 / 498(10 \cdot 6 \%) \\
49 / 382(12.8 \%)\end{array}$ & $1 \cdot 24(0.81-1 \cdot 89)$ \\
\hline
\end{tabular}

Ethnic identity of household

Bangladeshi $\quad 10 / 196(5.1 \%)$

$\begin{array}{lll}\text { Bihari } & 89 / 656(13.6 \%) & 2.91(1.53-5.52)^{* *}\end{array}$

Mixed $\quad 3 / 28(10.7 \%) \quad 2.23(0.61-8.11)$

Household respondent's ability to read

Able $\quad 22 / 269(8 \cdot 2 \%)$

$\begin{array}{ll}\text { Unable } & 22 / 269(8.2 \%)\end{array}$

Income of household per month ${ }^{b}$

$>1040$ BDT $42 / 451 \quad(9 \cdot 3 \%)$

$<1040$ BDT $\quad 60 / 429(14.0 \%)$

Site of respondent's defaecation

Own latrine $17 / 234 \quad(7 \cdot 3 \%)$

Shared latrine $\quad 18 / 233(7.7 \%)$

Community latrine $\quad 59 / 336(17.6 \%)$

Indiscriminate $\quad 8 / 71(11 \cdot 3 \%)$

Site of children's defaecation

$\begin{array}{lll}\text { Own latrine } \quad 18 / 217 \quad(8 \cdot 3 \%) & 0\end{array}$

Shared latrine $\quad 7 / 157(4.5 \%)$

Community latrine $35 / 194(18.0 \%)$

Indiscriminate $\quad 41 / 294(14.7 \%)$

Source of drinking water

Own well or tap $15 / 122(12.3 \%)$

Common well or tap $87 / 758(11.5 \%)$

Source of washing water

Own well or tap $15 / 137(10.9 \%)$

Common well or tap $87 / 743(11 \cdot 7 \%)$

Number living in household
$<4$
$\begin{array}{ll}5-8 & 77 / 636(12 \cdot 1 \%) \\ >9 & 19 / 135(14 \cdot 1 \%)\end{array}$
$6 / 109 \quad(5 \cdot 5 \%)$
$19 / 135(14 \cdot 1 \%) \quad 2.56(1 \cdot 02-4 \cdot 73)$

Time household has been in the community

$<10$ years $33 / 332(9.9 \%)$

$>10$ years

$69 / 548(12.6 \%) \quad 1.31(0 . \overline{8} 9-1.92)$

Type of floor

Cement

Earth

$12 / 214 \quad(5 \cdot 6 \%)$

Type of roof

Cement

Bamboo

Metal

$90 / 666(13 \cdot 5 \%)$

$2.63(1 . \overline{44}-4.81)^{* *}$

$2 / 54 \quad(3.7 \%)$

$21 / 211(10.0 \%)$

$2.87(0 \cdot \overline{70}-11 \cdot 79)$

$3.83(1.00-14 \cdot 90)^{*}$

Ascaris lumbricoides worm burden

$<13$ worms $\quad 47 / 469(10 \cdot 0 \%)$

$>13$ worms $\quad 55 / 411(13.3 \%)$

$1 \cdot 39(0-\overline{90}-2 \cdot 39)$

Hookworm infection

$\begin{array}{lll}\text { Absent } & 87 / 800(10.9 \%) & \\ \text { Present } & 15 / 80(18.8 \%) & 1.89(1 \cdot \overline{04-3.43})\end{array}$

"95\% confidence interval in parentheses. Significantly different results are indicated thus: ${ }_{P<0.05,{ }^{*} P<0.01,{ }^{*} P} P<0.001$ results are indicated thus:
$\mathrm{BDT}=$ Bangladesh taka.

more people use these latrines, so contamination of the ground by faeces from infected persons is expected to be greater. The risk of infection associated with having an earth floor suggests that some transmission of infection occurs within houses. Infective $S$.stercoralis larvae and other parasites have been detected on earth floors of houses in a slum community in Colombia, where the possibility of infection within households was also suggested (FAUST \& GIRALDO, 1960). Studies in Poland (SOROCZAN, 1976) and Jamaica (LINDO, 1992) have suggested that $S$.stercaralis infections are aggregated in particular households.

The prevalence of S.stercoralis infection is age-dependent. In this study, the highest proportion infected was in the 7-10 years age class. Available data from other studies in Bangladesh show a similar pattern. In child. 
ren, MUTtaliB et al. (1976) showed an increase in detected prevalence of S.stercoralis with age up to 8 years, and no further increase up to age 15. Surveillance of patients presenting to the diarrhoea hospital of ICDDR, $\mathrm{B}$ in 1989-1991 showed that the highest proportion with detectable infection was in the 5-9 years age class (Dr Salam, personal communication). A similar pattern of peak prevalence in older children has been observed in some studies in other countries (SORNMANI et al., 1973; CABRERA, 1981; MARIELL et al., 1992), although other studies have shown peak prevalence in adults (LAMY \& LAMY, 1954; FAUST \& GIRALDO, 1960; FouloN et al., 1979; PROKHOROV et al., 1983; WHITWORTH et al., 1991; ARAKAKI et al., 1992; AsHFORD et al., 1992). The underlying cause of these apparent differences in the relationship between age and infection in different communities is presently unclear. The possibility of age-dependent differences in risks of exposure to infection, which may differ between communities, has not been investigated.

The higher prevalence of infection among persons of Bihari ethnicity, which was independent of confounding factors of household hygiene, is probably due to other risk factors associated with poverty or social history which were not investigated in the present study (WHITAKER et al., 1982). This study did not detect a significant difference in prevalence between males and females, although some studies in other countries have shown significantly higher prevalences in males than in females (FAUST \& GIRALDO, 1960; CABRERA, 1981; ARAKAKI et al., 1992).

An accurate estimate of point prevalence of S.stercoralis in the study community cannot be derived from the present study, as the ether sedimentation technique employed is not very sensitive at detecting low intensity infections. The total proportion with detected infection at any of the 3 examinations is almost certainly closer to the real prevalence than the proportion at only one examination, as repeated examination increases sensitivity, and most Sistercoralis infections persist for considerably longer than one year, the period of the present study (JEFFERY, 1960). A more accurate estimation of prevalence could probably be obtained using either an agar plate method for faecal culture (KOGA et al., 1991), or a sensitive and specific immunodiagnostic test based on serum immunoglobulin G recognition of specific $S$. stercoralis larval proteins (CONWAY et al., 1993).

In conclusion, the results of the present study suggest that, in this urban slum community, transmission of $S$.stercoralis occurs mainly in the vicinity of community latrines, and also within households, where an earth floor is associated with an increased risk of infection. Changes in the household environment, particularly installation of sanitary facilities, and construction of a cement floor would probably reduce the Iransmission of $S$ stercoralis infection. Even with the interruption of transmission, in the absence of chemotherapy, prevalence would be expected to decline only slowly, due to the longevity of in dividual infections (SATO, 1986). Oral administration of $400 \mathrm{mg}$ albendazole daily for $3 \mathrm{~d}$ is safe and $60-80 \%$ ef fective at curing $S$.stercoralis infections, and is currently recommended by World Health Organization guidelines (WHO, 1990). Mass chemotherapy can reduce community prevalence effectively (ARGUEDAS et al., 1975; GOULART et al., 1977), although chemotherapy targeted to risk groups, or given selectively to those with detecred infections, might provide more economical alternatives. The significance of $S$.stercoralis infection as a public health problem needs to be assessed more accurately before these options for community control can be properly evaluated.

\section{Acknowledgements}

We thank Don Bundy and Afif Ben Salah for their helpful comments on a draft of the manuscipt, and gratefully acknowledge support from the Wellcome Trust. The data analysed in this paper were obtained in a study funded by the British Over- seas Development Administration and the Lnited States AID Project Development Fund of the ICDDR, $B$. The ICDDR, $B$ is supported by countries, agencies and organizations which share its concern for the health problems of people living in developing countries. Current donors include the governments of Australia, Bangladesh, Belgium, Canada, Denmark, France, Japan, the Netherlands, Norway, Sweden, Switzerland, the UK, and the USA, and international agencies including the UNCDF, UNDP, LNKCEF, WHO, and the Ford Foundation.

References

Arakaki, T., Kohakura, M., Asato, R., Ikeshiro, T., Nakamura, S. \& Iwanaga, M. (1992). Epidemiological aspects of Strongyloides stercoralis infection in Okinawa, Japan. Joumal of Tropical Medicine and Hygiene, 95, 210-213.

Arguedas, G. J. A., Villarejos, V. M., Swartzwelder, J. C., Chavarria, A. P., Zeledon, R \& Kotcher, E. (1975). Community control of Strongyloides stercoralis by thiabendazole. Texas Reports on Biology and Medicine, 33, 265-268.

Ashford, R. W., Craig, P. S. \& Oppenheimer, S. J. (1992). Polyparasicism on the Kenya coast. 1. Prevalence, and association between parasitic infections. Anrals of Tropical Medicine and Parasitology, 86, $671-679$.

Banki, G., Lengyel, A., Zoltai, N. \& Vilimszky, Z. (1963). Eradication of endemic strongyloidiasis in infant and mental hygenic homes in Hungary. Helminthologia, 4, 51-56.

Cabrera, B. D. (1981). Prevalence of Strongyloides stercoralis infection in selected areas in the Philippines using a modified Harada-Mori culture technique. In: Collected Papers on the Control of Soil-Transmitted Helminthiases, vol. 2. Tokyo: Asian Parasite Control Organization, pp. 19-26.

Conway, D. J., Bailey, J. W., Lindo, J. F., Robinson, R. D., Bundy, D. A. P. \& Bianco, A. E. (1993). Serum IgG reactivity with 41-, 31-, and 28-kDa larval proteins of Strongyloides stercoralis in individuals with strongyloidiasis. Foumal of Infectious Diseases, 168, 784-787.

Cornejo, J., Arias, B., Subaire, V., Quijada, M. \& Schenone, H. (1985). Estudio epidemiologico de protozoosis y belmintiasis intestinales en 490 pacientes cronicos del hospital Psiquiatrico de Putaendo V Region, Chile, 1985. Boletino Chileno de Parasitologia, $40,91.93$.

Faust, E. C. \& Giraldo, L. E. (1960). Parasitological surveys in Cali, Departmento del Valle, Colombia. VI. Strongyloidiasis in Barrio Siloe, Cali, Colombia. Transactions of the Royal Society of Tropical Medicine and Hygiene, 54, 556-563.

Foulon, G., Villion, A., Diaz, C. \& Derville, M. (1979). Etude de l'Endemie Parasitaire Intestinale dans le Départements de Outre-met. 1. La Martinique, Le Vesinet, France: Institut doutre-met.
National de la Santé er de la Recherche Médicale.

Goulart, E. G., Jourdan, M. C., Brazil, R. P., Brazil, B. G., Cosendy, A. E., Bar, M., Do Carmo, E. C. \& Gilbert, B. (1977). Ecological control of hookworm and strongyloidiasis. foumal of Helminthology, 51, 131-132.

Grove, D. I. (1989a). Clinical manifestations. In: Strongyloidiasis: a Major Roundworm Infection of Man, Grove, D. I. (editor). London: Taylor \& Francis, pp. 155-173.

Grove, D. I. (1989b). Treatment. In: Strongyloidiasis: a Major Roundtsorm Infection of Man, Grove, D. I. (editor). London: Taylor \& Francis, pp. 199-231.

Hall, A. (1981), Quantitative variability of nematode egg counts in faeces: a study among rural Kenyans. Transactions of the

Hall, A., Anwar, K. S. \& Tomkins, A. M. (1992). Intensity of reinfection with Ascaris lumbricoides and its implications for parasite control. Lancet, 339, 1253-1257.

Jeffery, G. M. (1960). A three year epidemiologic study of intes. tinal parasites in a selected group of mental patients. American foumal of Hygiene, $71,1-8$.

Kirkwood, B. R. (1988). Essentials of Medical Statistics. Oxford: Blackwell Scientific Publications.

Koga, K., Katsuya, S., Khamboonruang, $C$., Sukhavat, $K$, leda, M., Takatsua, N., Kita, K. \& Ohtomo, H. (199). A coralis. American foumal of Tropical Medicine and Hygiene, 45 , 518-521.

Lamy, L. \& Lamy, H. (1954). Donnes actuelles sur le parasitisme intestinale et sanguin des différentes populations Africaines de l'agglomération de Brazzaville. Annales de l'Institut Pasteur, 4, 465-478.

Lindo, J. F. (1992). Studies of the epidemiology of human Strongyloides stercoralis infection at endemic foci in famaica. $\mathrm{Ph} . \mathrm{D}$. thesis, University of the West Indies.

Marnell, F., Guillet, A. \& Holland, C. (1992). A survey of the intestinal helminths of refuges in Juba, Sudan. Annals of Tropical Medicine and Parasitology, 86, 387-393.

Muttalib, M. A., Islam, N. \& Islam, S. (1976). Prevalence of in- 
testinal parasites in rural children of Bangladesh. Bangladesh Medicalfoumal, 5, 9-27.

Prokhorov, A. F., Isupov, Y. I. \& Golovan, T. V. (1978). [A study of foci of strongyloidiasis in a home for patients with nervous disorders.] Meditsinskaya Parazilologiva i Parasitarnve Bolemi, 47, 99-102 (in Russian).

Prokhorov, A. F., Isupov, Y. I., Golovan, T. V., Strikhanova, E. V., Fuki, A. D., Murashov, N. E., Tsegoeva, V. K., Doeva, I. T., Lagiev, M. T. A., Cafurov, R. S. \& Ionov, S. S. (1983). [Epidemiology of strongyloidiasis in the North Caucasus.] Meditsinskaya Parazitologiya i Parazitarnye Bolezni, 61, 34-38 (in Russian).

Sato, Y. (1986). Epidemiology of strongyloidiasis in Okinawa. In: Collected Papers on the Control of Soil-Transmitted Helminthiases, vol. 3. Tokyo: Asian Parasite Control Organization, pp. $20-31$.

Sornmani, S., Vivatanasesth, P., Bunnag, T., Intarakha, C. \& Harinasuta, C. (1973). A study on the pattern of socioeconomic and health status in relation to parasitic diseases in the inhabitants around Ulobratana dam in northeast Thailand. Southeast Asion Joumal of Tropical Medicine and Public
Healsh, 4, 421-434.

Soroczan, W. (1976). Strongyloides stercoralis in eastern and south-eastern Poland. Wiadomosci Parazytologiczne, 22, 515 516.

Whitaker, B., Guest, I, a doctor, \& Ennals, D. (1982). The Biharis in Bangladesh, 4th edition. London: Minority Rights Group Report, no. 11 .

Whitworth, J. A. G., Morgan, D., Maude, G. H., McNicholas, A. M. \& Taylor, D. W. (1991). A field study of the effect of ivermectin on intestinal helminths in man. Transactions of the Royal Society of Tropical Medicine and Hygietie, 85, 232-234.

WHO (1990). Model Prescribing Information: Drugs Used in Parasinic Diseases. Geneva: World Health Organization.

Yoeli, M., Most, H., Berman, H. H. \& Tesse, B. (1963). The problem of strongylojdiasis among the mentally retarded in institutions. Transactions of the Royal Society of Tropical Medicine and Hygiene, 57, 336-345.

Received 3 August 1993; revised 8 September 1993; accepted for publication 9 September 1993

\section{Announcement}

\section{PRIZES}

\section{UNDERGRADUATE PROJECT PRIZE}

The Royal Society of Tropical Medicine and Hygiene offers an annual prize of £200 for an account of work carried out in a tropical or developing country by a non-medical student of any nationality. The work will add to the knowledge of human or veterinary health or hygiene in the broadest sense. Particular atten tion will be directed towards originality and quality in the award of the prize. It is anticipated that the prize will act as a stimulus for the pursuit of excellence in research carried out by undergraduates.

\section{MEDICAL STUDENT ELECTIVE PRIZE}

The Royal Society of Tropical Medicine and Hygiene offers an annual prize of $\Sigma 200$ for an account of work carried out by a medical student of any nationality during an elective period spent in a tropical or developing country. In awarding this prize emphasis will be laid on the originality of the work and on its con. tribution to knowledge or understanding of tropical diseases.

\section{RULES}

1. Two prizes of $\mathbf{2} 200$ may be awarded annually in recognition of outstanding projects which increase knowledge of tropical medicine and hygiene in the broadest sense.

2. Candidates shall be nominated by their head of department, supervisor or Dean, with a supporting statement of up to 500 words.

3. The closing date for receipt of project reports is 31 December. The project should have been done or completed in the previous twelve months.

4. A Committee of three shall choose the prize winners.

5. The announcement of the prize winners will be made at the March meeting of the Society.

6. The prizes will be presented by the President of the Society at the Annual General Meeting in June or July.

Please note that the Society cannot provide funds to cover students' elective travel expenses. 